\title{
Abandoning Innovation in Emerging Industries
}

\author{
Rajshree Agarwal • Barry L. Bayus • Mary Tripsas
}

Published online: 18 April 2014

(C) Springer Science+Business Media New York 2014

\begin{abstract}
Existing models of industry evolution describe a smooth pattern over time in which initial growth in the number of firms is followed by a sharp decrease due to a shakeout and an eventual stabilization as the industry reaches maturity. Although this model has been well accepted and supporting empirical finding holds true across a range of industries, we propose an alternative pattern of evolution in which, during the emergent stage, a new industry experiences a sharp decrease in the number of firms - a "mini shakeout"-before increasing again, reaching a final peak and undergoing a major shakeout as described in the extant literature. Using data across multiple product innovations introduced in the twentieth century, we show the pervasiveness of the mini shakeout phenomena. Using detailed quantitative and qualitative data on the emergence of handheld computers and digital cameras, we then investigate why some firms abandon innovation before an industry even develops while others stay committed. We propose a conceptual model that highlights the role of unmet expectations and the degree of importance of the emerging industry to the focal firm in determining its likelihood of exit from the emerging industry.
\end{abstract}

All authors contributed equally and are listed in alphabetical order.

R. Agarwal

Robert H. Smith School of Business, University of Maryland, 4512

Van Munching Hall, College Park, MD 20742, USA

e-mail: rajshree@umd.edu

B. L. Bayus $(\bowtie)$

Kenan-Flagler Business School, University of North Carolina,

McColl 4526, Chapel Hill, NC 27599, USA

e-mail: barry_bayus@unc.edu

\section{Tripsas}

Carroll School of Management, Boston College, Fulton Hall 426A, Boston, MA 02467, USA

e-mail: tripsas@bc.edu
Keywords Industry life cycle · Firm exit · Shakeout · Industry evolution

\section{Introduction}

The industry life cycle is one of the most influential models in the literature concerned with the evolution of new industries (see [56] for a recent review). The seminal paper in this research stream by Gort and Klepper [33] portrays the diffusion of product innovations in terms of the number of firms that exist in a new industry over time. Since then, an impressive body of research, spanning across technology management, organizational ecology, evolutionary economics, and marketing, has documented evidence of an inverted Ushaped relationship of number of firms over time $[5,15,21$, $45,76]$. The literature on technology and industry evolution divides the industry life cycle into three stages: growth, shakeout, and maturity $[9,13,56]$. These stages have alternatively been labeled as variation, selection and retention [77], fluid, transitional and specific [75], era of ferment, dominant design, and era of incremental change [74].

Figure 1 provides a stylized illustration of entry, exit, and the total number of firms over the course of the industry life cycle. The earliest stage is characterized by significant growth in the number of firms in the industry since entry exceeds exit. For example, Agarwal and Gort [8] find that, on average, annual entry rates in the early years are at least four times higher than the annual exit rates. In direct contrast, the shakeout stage is characterized by a sharp decline in the number of firms, with annual exit rates on average three times higher than annual entry rates. Researchers have attributed the shakeout phenomenon in industry life cycles to an increased emphasis on process vs. product innovation, economies of scale and production efficiencies, and standardization on a dominant 
Fig. 1 Stylized facts of industry evolution

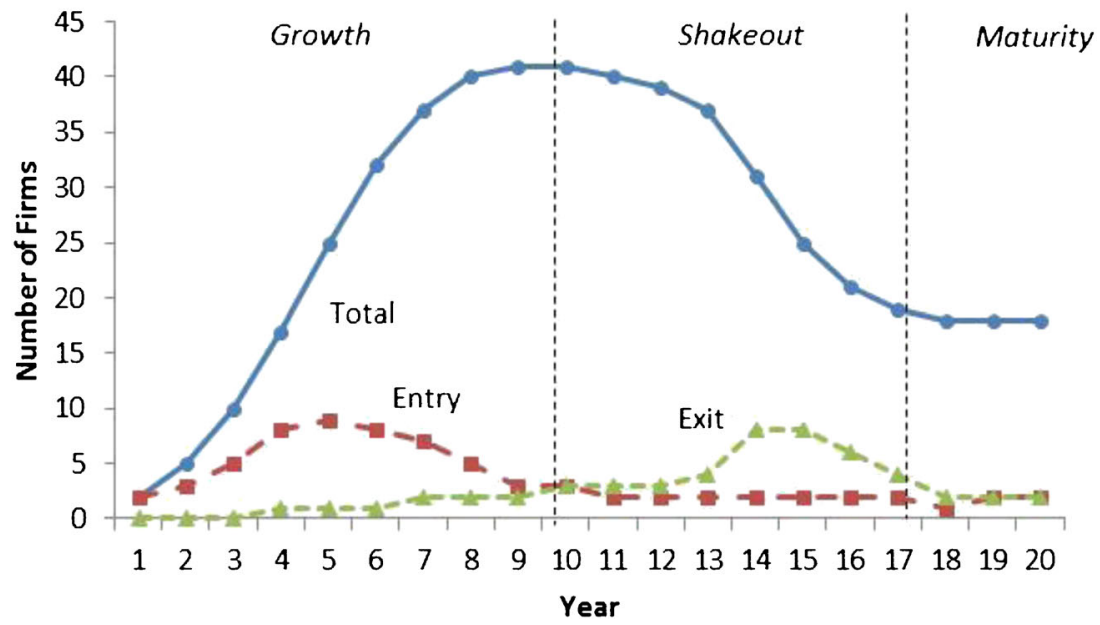

design $[2,33,40,43]$. The final mature stage occurs when an "equilibrium" number of firms is reached, representing relatively stable technological activity, with entry rates roughly equal to exit rates.

The relatively smooth inverted U-shaped depiction of the number of firms over time in Fig. 1, however, can mask significant turnover in the firms operating in the industry. For example, scholars have acknowledged the high degree of technological and market uncertainty facing firms that enter emerging industries $[19,61,74,75]$. And, related literature on first mover (dis) advantages discusses the risks of pioneering and has documented significant failure rates for pioneering firms [30,55]. This work calls into question the smoothness of the initial increase in the number of firms during the early stages of the industry life cycle and suggests that there might be considerable churn and turbulence experienced by early entrants.

In this paper, we explore the early growth stage in depth and, in doing so, propose an alternative model of industry evolution in which there are two additional stages, a mini shakeout and subsequent resurgence in firm growth that precede the final shakeout (see Fig. 2). A mini shakeout is a sharp decline in the number of firms over successive periods during the emergence stage of a new industry ${ }^{1}$. The existence of a mini shakeout signals that an emerging industry has a lot of uncertainty about consumer preferences. The early commercialized forms of new innovations are generally quite primitive $[5,44]$. Not surprisingly, competition during the early

\footnotetext{
${ }^{1}$ The introduction of radical new technology in an industry often results in new waves of firm entry and exit $[22,42,54,70]$. However, the deviations from the smooth industry evolution curves emphasized in these studies occur after the legitimacy of the industry when both demand and supply in the market are well established. In fact, Abernathy et al. [1] use the term "de-maturity" to describe such changes in the automobile industry.
}

stages of market growth is primarily on the basis of continued product improvements. Early entrants often have very different ideas on product design and technology that will be desired by consumers [33]. For example, should a handheld computer have keyboard, pen, voice, or touch screen input? Given market uncertainty in exactly what product design and technology is desired, experimentation with product offerings that combine features and attributes in various ways is important. While it is possible for large firms with sufficient resources to learn consumer preferences over time by commercializing several product variants, more often, a dominant product design evolves from product experimentation across early entrants [51]. Thus, a mini shakeout can signal that firms in the emerging industry have reached a consensus on product design and technology, and thus, a takeoff in sales is imminent.

We seek to address two questions in our research: (1) How prevalent is the mini shakeout phenomenon, and what characterizes industries that exhibit this alternative pattern of evolution? (2) Why do some firms exit an industry even as it is evolving and becoming profitable? To address these research questions, we begin with an investigation of data on the early life cycle stages for 24 new industries ${ }^{2}$. We examine the number of entries and exits during the emergence stage of each industry, and identify which industries experienced a mini shakeout - a significant exodus of firms in these formative years. We then turn to an inductive analysis of two emerging industries, digital cameras, and handheld computers, to explore the firm exit decision at a deeper level. We examine industry, firm, and group/individual-level factors that influence firm decisions to abandon an emerging industry. In

\footnotetext{
${ }^{2}$ For information on all life cycle stages for most of the industries included in the sample, see Agarwal [4].
} 


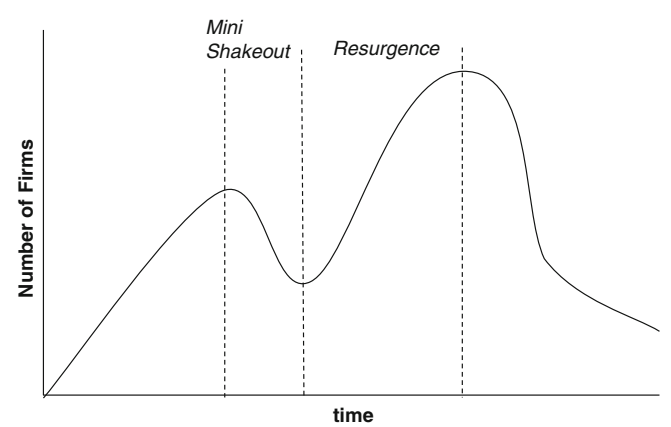

Fig. 2 An alternative pattern of industry evolution

doing so, we highlight two related variables contributing to the exit decision: first, the level of the firm's unmet expectations, i.e., the disparity between expected and actual development of the industry, and second, the strategic importance of the industry to the firm. Finally, we examine the applicability of these two factors for one firm's decision to abandon innovations after a significant investment of resources.

Our study makes several important contributions. We contribute to the innovation diffusion and industry evolution literatures by documenting the extent to which industries may deviate from generally accepted stylized patterns. We find that a significant number of industries experience a mini shakeout early in their life cycle, as contrasted with the shakeout that occurs after the industry has experienced significant growth in both number of firms and sales. Thus, we propose that an alternative evolutionary path may apply in some contexts. Rather than three distinct stages with a clear increase, shakeout, and decline in the number of firms, we propose two additional stages - a mini shakeout and subsequent increase in firms - that precede the final shakeout.

We contribute to the technology strategy literature by identifying factors that may cause firms to choose exit, even in the early stages of the industry. While a great deal of work has focused on entry into an industry as a firm choice [33, 37, 54], the implicit assumption of most survival analyses is that "winners" survive and "losers" exit. In this literature, exit is not a choice but a necessity that plays out as competition intensifies and the industry matures. Thus, the focus of much research has been on understanding why some firms outperform others in adapting to new technology that results in a new industry $[18,62,67]$. We add to this literature stream by proposing that firms sometimes choose to abandon their innovation efforts and exit an emerging industry before it is even clear who are the winners and losers. Our focus is therefore not on why some firms outperform others, but on why some firms choose to exit and others choose to persist when performance signals are ambiguous. Our paper also provides insights into how firms interpret signals as they navigate an uncertain environment and react to unmet expectations. In doing so, we enhance our understanding of why firms abandon particular industries early in the life cycle.

\section{The Mini Shakeout Phenomenon: How Pervasive Is It?}

Empirically, there have been relatively few studies that provide systematic documentation of the degree to which significant exodus may occur in emerging industries. This partly stems from the difficulty in obtaining accurate historical data on multiple industries. Another reason may be that the emergence stage has not been the primary focus of most evolutionary studies, since research in this vein has largely focused on time trends across all stages of the life cycle and firm performance, and the emergence of oligopolistic market structures at maturity (see review by [7]).

\subsection{Data and Methods}

In this section, we measure firm exit during the emergence stage (defined as the stage from inception of industry to sales takeoff $)^{3}$ and document evidence for what we term the "mini shakeout" phenomenon, i.e., a significant decline in the number of firms operating in the industry and over successive periods. We use data for 24 industries to better understand the mini shakeout phenomenon. The data come from the Agarwal and Bayus [5, 6] sample of 22 industries as well as two more recent industries - digital cameras and the handheld computing. The industries in our study represent major product innovations that were introduced starting with the late nineteenth century and extending to 1984. These industries are largely a subset of the 46 industries in the Gort and Klepper [33] sample ${ }^{4}$. The data were compiled mainly from the Thomas Register of American Manufacturers. Supplementary information was obtained from the Census of Manufactures and a variety of trade publications (e.g., Merchandising Week). Greater details of the data are in Agarwal and Bayus [5].

It is important to note that these data were originally developed for research that did not focus on exit in the emergence stage of a new industry. The initial list of product innovations was created by consulting various technical sources, scientific journals, chronologies, and encyclopedias

\footnotetext{
${ }^{3}$ While most industry evolution studies identify one stage that combines both emergence and growth, we break them out and define the emergence stage as the period between the first commercial introduction of an innovation and a takeoff in its sales. Studies in marketing that focus on sales diffusion have identified sales takeoff, a sharp increase in sales that follows an initial period of slow growth, as a key turning point [31, 51, 59]. Further, Agarwal and Bayus [5] show that firm takeoff systematically precedes sales takeoff in all the industries they study. Firm takeoff represents legitimacy of the industry on the supply side, while sales takeoff represents legitimacy of the industry on the demand side. We therefore choose sales takeoff as the defining moment for the end of the emergence stage since at that point, both supply and demand uncertainty has been addressed.

${ }^{4}$ Lack of consistent data for both firms and sales precluded the other 24 industries from being added to our analysis.
} 
of new innovations. To be included in the sample, a product innovation had to be deemed significant by experts in the field, result in entirely new industries, or be based on discontinuous technologies rather than represent improvements or sub-sections of existing industries [33]. Thus, the choice of industries was made in the absence of any prior knowledge or expectation about the length of either the takeoff times or the amount of exit that occurred during the emergence stage.

\subsection{Findings}

Consider the four industries shown in Fig. 3. In each panel, we focus on the emergence stage of the industry. The number of competing firms and total industry sales are plotted over time. Particularly noteworthy in all four industries is a period of consistent decline in the number of firms, which occurs before the takeoff in sales. Thus, these graphs show that many firms chose to exit the industry in a relatively short period of time. Are these industries exceptions to the rule, or is the observed phenomenon more pervasive than one would believe? We turn to Table 1 to address this question.

Table 1 provides descriptive statistics regarding the year of commercial introduction, the firm and sales takeoff years, the number of entries, and the number of exits for each industry in our sample. We follow the methodology described in Agarwal and Bayus [5] to determine the year of sales takeoff and number of firms for each industry in our sample. Regardless of when an innovation was first introduced, there is significant variation in length of the emergence stage (the time to sales takeoff) across industries. Additionally, there is wide variation in the number of firms that enter during the emergence stage. While the average number of entrants across industries is 31 , some industries have only a few entrants, while others experience significant entry.

We define an industry to have experienced a mini shakeout if, in the period between commercial introduction and time of sales takeoff, it experiences either (a) at least a $20 \%$ reduction in the number of firms over at least a two consecutive year period or (b) a more than $50 \%$ reduction in 1 year. Based on this definition, $46 \%$ of the industries in our sample experience a mini shakeout during the emergence stage. On an average, the duration of the mini shakeout lasts 2.5 years and results in a $40 \%$ decline in the number of firms in the industry. Further, five of 11 industries experience more than a $50 \%$ decline in the number of firms during the mini-shakeout period. Importantly, these high percentages are not a function of low denominator values; all industries that experience a mini shakeout have double digit entrants prior to the emergence stage.

Exit, however, is not confined to the mini shakeout period; we observe it throughout the emergence stage. Table 1 documents the rate of churn for each industry, defined as the ratio of cumulative number of exits to the cumulative number of entrants during the emergence stage. Interestingly, industries such as compact disc players that exhibit zero rates of churn are an exception rather than a rule. On an average, $38 \%$ of the firms that enter prior to sales takeoff also exit prior to sales takeoff, with the rates of churn being higher than $50 \%$ for nine of the 24 industries. Thus, the relatively smooth increase in the

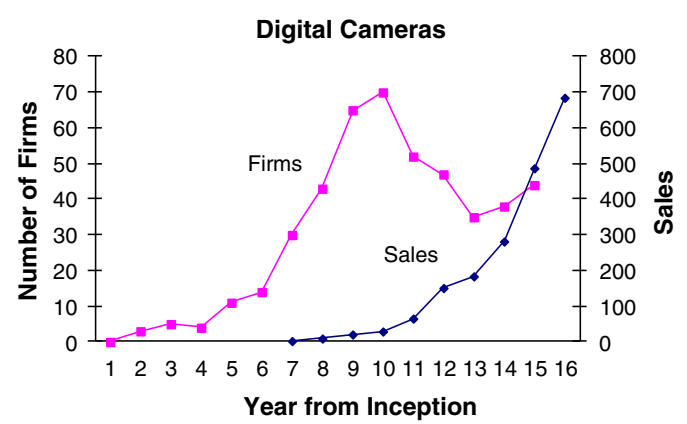

Freon Compressors

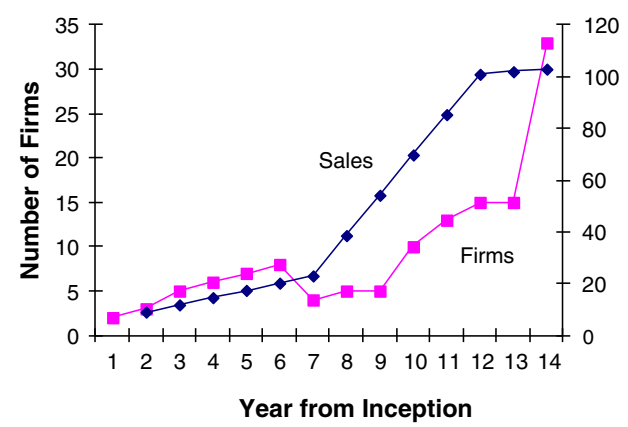

Fig. 3 Examples of the mini shakeout phenomenon
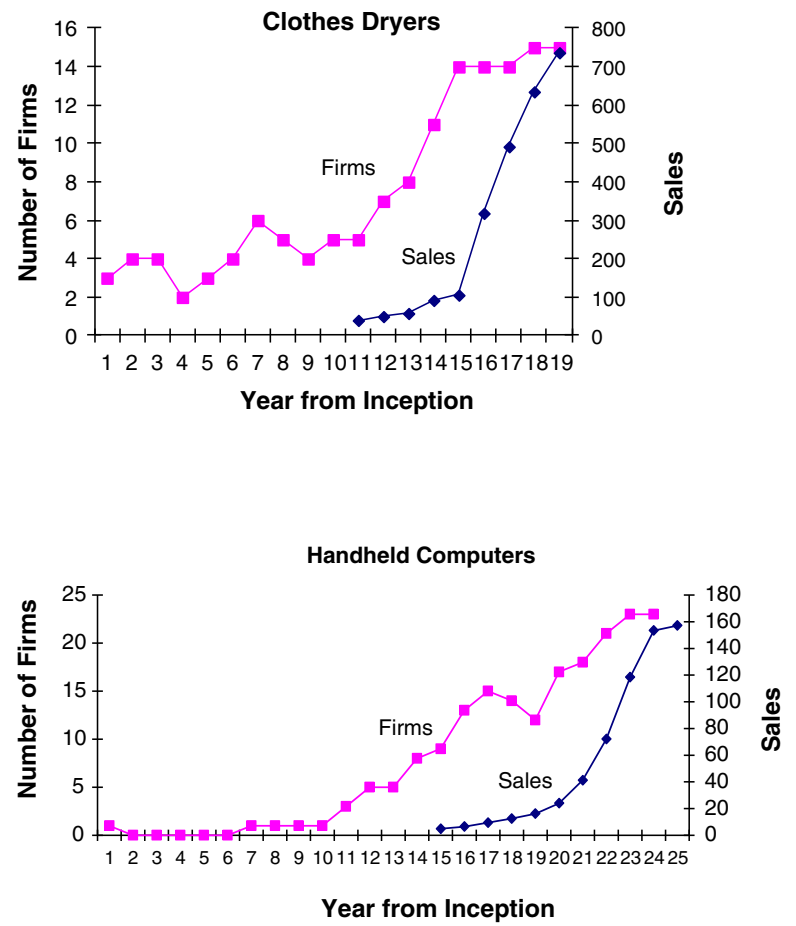


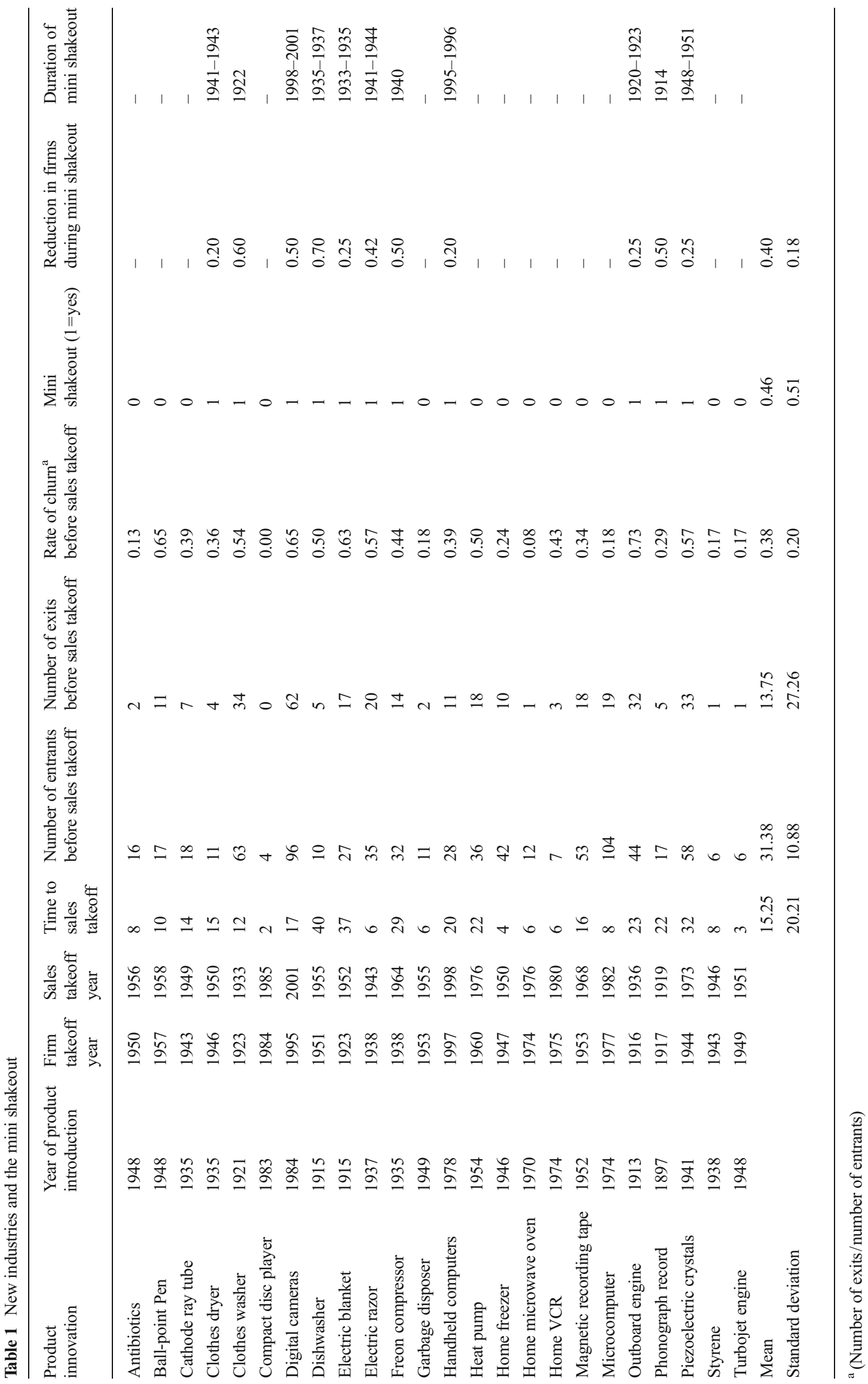


number of firms described in earlier studies masks significant turnover in the firms that operate in a new industry.

It is also worthwhile to compare the statistics reported above on the mini shakeout to the findings on the shakeout experienced in an industry after its legitimacy has been established and it has entered the growth period. Gort and Klepper [33] report that $80 \%$ of the industries in their sample experienced a major shakeout. While the percent of industries experiencing a mini shakeout in our sample is much lower, the decline in the number of firms in each period is roughly comparable. In particular, the average decline in the number of firms during the major shakeout is $40 \%$, and the range across industries varies from a low of $19 \%$ to a high of $77 \%$. Based on Table 1, the average decline in firms during the mini shakeout is also $40 \%$, and the range across industries varies from a low of $20 \%$ to a high of $70 \%$. Thus, the magnitude of the exodus in the emergence stage, for the industries that do experience a mini shakeout, is close to what is observed when the industry enters a consolidation stage.

While our data do not allow us to statistically test what factors explain why some industries follow this alternative pattern of evolution, descriptive data suggest that the time an industry takes to develop may be important. Based on a simple calculation of mean values, the time from initial commercialization of a product to sales takeoff is 21 years for industries that experience a mini shakeout vs. only 8.5 years for industries that do not. This finding is not surprising since one might expect that some managers would lose patience and abandon an industry that is taking too long to develop. But, what distinguishes firms that abandon the emerging industry from those that stay the course?

\section{Why Do Firms Exit an Emerging Industry?}

In this section, we use inductive theory building through case studies $[25,79]$ to explore potential underlying causes of the mini shakeout in two industries: digital cameras and handheld computers. We compiled quantitative and qualitative data on both industries from company press releases, annual reports, SEC filings, web sites, media articles, industry research reports (e.g., IDC, Gartner), and Wall Street analyst reports as well as private company archives. For each industry, we gathered data on the entire population of firms including the timing of firm entry and/or exit, firm size, and if applicable, the industries in which they operated in prior to entry into the focal industry. We focused on the period surrounding entry into the focal industry and if applicable, surrounding exit, examining reactions about entry and/or exit.

In analyzing this data, we began by categorizing each firm based on its prior affiliation. Digital camera firms were categorized as either start-ups, photography, consumer electronics, computing, or graphic arts firms, and handheld computing firms were categorized as start-ups, telecommunications, personal computer, or consumer electronics firms. We then compared firms that exited and those that did not in order to identify patterns based on prior industry affiliation. We next analyzed each firm. We examined all press releases and articles within the 2-month period before and after the entry and exit of each firm in the sample as well as SEC filings and annual reports and coded reasons identified for entry and exit looking for common patterns. Finally, for a subset of firms for which we had data about internal firm dynamics, we explored the rationale of individual managers or groups within the firm.

\subsection{Digital Imaging}

As reported in Table 1, the first digital camera was available on the market in 1984. The camera, introduced by Eikonix-a firm that sold prepress systems to the graphic arts industrywas expensive at about US $\$ 20,000$ and needed a dedicated mini-computer that costs US\$30,000 to store and process images. The graphic arts industry had already begun to digitally scan analog images for publishing, and Eikonix perceived an opportunity for direct digital capture. The market for the camera, however, was slow to develop. Kodak acquired Eikonix in 1985, but exited the digital camera market in 1989. "The market just wasn't there for cameras," commented management at the time [49]. Kodak and other photography firms, however, continued to invest in digital imaging technology in preparation for when the industry did develop. Kodak invested approximately US\$5 billion over 10 years throughout the 1980 s and, along with Fuji, reentered the market in 1991. Other photography firms followed their lead, and by 1995, 12 more photography firms had entered the digital camera industry. Entrants from other industries such as computers and consumer electronics waited until 1997 when a large wave of 23 firms entered. The expectation at that time indicated that the market (sales) was on the verge of taking off. An article in one of the industry's trade journals noted, "Most market watchers believe 1997 will be the year that makes scanners and digital cameras as ubiquitous as color printers have become" [11]. Despite this optimism, however, sales did not accelerate until 2001. By this time, however, $55 \%$ of the entrants had given up and exited the industry.

\subsection{Handheld Computing}

The handheld computing industry experienced a similar phenomenon. Typical of really new innovations, the handheld computing devices commercialized in 1978 had to considerably improve before widespread market acceptance was to occur almost 20 years later $[15,46]$. Firms in three different industries (consumer electronics, personal computers, telecommunications) considered this opportunity to be the next big thing [10]. This "could be the hottest new product, or 
product category, since the PC arrived on the scene in the late 1970's," said Andrew Seybold, newsletter editor of Seybold's Outlook on Professional Computing [47]. Excitement about the potential of this new industry attracted 20 entrants between 1991 and 1994, including established companies like HP, Apple, Tandy, Sony, AT\&T, Bell South, and Motorola as well as start-ups like Momenta $[15,66]$. However, despite all this attention, most potential buyers ignored the initial product offerings. Sales followed a hockey-stick pattern: initial sales were relatively low for several years before the takeoff finally occurred in 1998. But this delay had its impact; almost $40 \%$ of the early entrants abandoned the industry before substantial sales were achieved.

\subsection{Factors Influencing a Firm's Early Exit Decision}

Using these two industries, we now propose a framework for thinking about a firm's exit decision. We posit that exit before and during the mini shakeout is fundamentally different from the major shakeout. As characterized in the extant literature, when the major shakeout occurs, the market has already developed, with industry sales having taken off and stabilized. The drivers of exit in this situation have been primarily attributed to increased competition. Larger firms that reap the benefits of economies of scale [43] or organizational forms that have better fit [35] survive.

In contrast, firms exiting during the mini shakeout do so even before the market is fully developed. Why would a firm enter an emerging industry and then abandon it before the market materializes? While some firms (e.g., start-ups) run out of resources and are forced to exit, for established firms, abandoning the emerging industry is an explicit choice. Our primary interest is to better understand what distinguishes firms that remain in a new industry and wait for the market to develop from those that choose to exit before the industry takes off.

In analyzing exit before and during the mini shakeout, we identify two primary, but related, factors that drive the exit decision. The first concerns "Unmet Expectations," i.e., the disparity between a firm's expectations about the industry's development and the industry's actual development. The second concerns the "Strategic Importance of the Emerging Industry" to the firm. As summarized in Table 2, our detailed analyses of the digital imaging and handheld computing industries indicate that each of these two factors is influenced by industry-level, firm-level, and intrafirm-level considerations. We discuss each of these in turn.

\subsubsection{Unmet Expectations}

Firms enter an emerging industry with an expectation that there is an opportunity to be exploited. This belief is predicated on a number of assumptions about the expected evolution of the industry-assumptions about how quickly the market will grow, how technologies will perform, what customers will value, how competitors will respond, etc. Firms develop these assumptions under conditions of high uncertainty, and we therefore expect to find a substantial amount of variance in the ex-ante beliefs of firms. This variance is important since unmet expectations are key to explaining a firm's decision to abandon an emerging industry: a firm that justified its entry into a new industry based on aggressive forecasts will experience greater disappointment if the industry actually develops more slowly.

Firms that enter an emerging industry from an existing industry are influenced by the norms and beliefs of their prior affiliation [58]. In digital imaging, Benner and Tripsas [17] found that, depending on their prior industry, firms formed different initial interpretations about what a consumer digital camera was: photography firms framed it as a substitute for an analog camera, computing firms framed it as a PC peripheral, and consumer electronics firms framed it as just another consumer electronics device. We argue that firms from different prior industries also have varying expectations about the industry growth since firms from each of these prior industries looked to different sources for information and projections and used different methodologies. For example, the Photo Marketing Association (PMA) was one of the key sources of information for firms in analog photography. In October 1996, the PMA issued a conservative forecast of 1.2 million digital camera units to be sold in 1999 and 1.8 million in 2000. The methodology employed was to project how quickly digital cameras would substitute for analog cameras. In stark contrast was the forecast by International Data Corporation (IDC), a research firm that covered a broad range of computing and communications industries. Their forecast in August 1997 was that the industry would reach sales of four million units by 1999 and ten million units by 2000 . These widely divergent forecasts influenced the formation of very different expectations for photography firms as opposed to computing firms regarding the development of the digital camera market. Indeed, an internal planning document of one computing firm in 1998 showed an estimated market size of 22 million digital cameras by 2000 , based on a methodology that started with projections of the size of the PC industry and then projected what percentage of PC owners would have a digital camera "attached" to their PC. This methodology is consistent with Benner and Tripsas' [17] finding that computing firms conceived of a digital camera as a "PC peripheral." Thus, the shared beliefs of managers from firms in the same prior industry can certainly affect expectations about market size and growth in an emerging industry.

Further, even after accounting for industry level differences, firms can have divergent expectations about demand in the emerging industry since idiosyncratic firm history influences these expectations. For example, Sony, a firm with a 
Table 2 Why Do Some Firms Abandon an Emerging Industry?

\begin{tabular}{|c|c|c|}
\hline & Different expectations about customers & Different views of strategic importance \\
\hline Industry-level drivers & $\begin{array}{l}\text { - Shared industry beliefs about customer needs } \\
\text { and technologies create overly optimistic beliefs } \\
\text { about the market opportunity } \\
\text { - Widely differing forecasting methodologies } \\
\text { and predictions are available }\end{array}$ & $\begin{array}{l}\text { - The emerging industry is only viewed } \\
\text { as a diversification opportunity }\end{array}$ \\
\hline Firm-level drivers & $\begin{array}{l}\text { - The firm has no history of investing in } \\
\text { emerging industries } \\
\text { - The firm only targets large market segments }\end{array}$ & $\begin{array}{l}\text { - The emerging industry is not core to } \\
\text { the firm's identity }\end{array}$ \\
\hline Intra-firm drivers & $\begin{array}{l}\text { - Top management and functional managers } \\
\text { have very different perceptions of the market }\end{array}$ & $\begin{array}{l}\text { - The personal stakes for managers } \\
\text { are not aligned }\end{array}$ \\
\hline
\end{tabular}

track record of experimentation in new industries, had limited goals for its initial handheld, the Magic Link, which shipped in 1994. At the time, Tim Bajarin, then president of Creative Strategies, commented [16], "The Magic Link in this first iteration will not succeed in the consumer marketplace. I have to say that I don't think Sony is expecting it to do wonderful things in the consumer market. I think they've planned this quite well because their expectations are modest. They're learning what needs to be done for the second and third generation."

A second firm level factor that influences expectations is the selection of the target market within the emerging industry. For example, consider the early entrants in the handheld computing industry $[15,32,51]$. Expected market potential varied by whether initial customers were located in horizontal (consumer) or vertical (business) markets. The market size for individual use of personal electronic devices was the largest (e.g., in 1993, there were about 16 million US cellular phone subscribers, 19 million pager users, and 17 million computers in homes), followed by mobile business professionals (e.g., in 1993, there were about 6 million business people who are early adopters of technology), with customized business applications representing a very small segment (e.g., only a few thousand sales professionals, delivery drivers, physicians). Thus, firm expectations about potential sales were clearly dependent on the targeted market.

According to David Hennell, Amstrad's director of international marketing in 1994, Amstrad was looking for a "mass market avalanche" to create "almost impulse purchases" [32]. From their advertising campaign, AT\&T targeted at a broad class of users who might be engaged in "calling up an article on a national politician's speech, watching video highlights of a football match, scribbling a note and faxing it to your office, calling up your bank account, TV schedules and a hundred other services" [37]. Similarly, Tandy targeted their Zoomer device to the consumer market [39]. On the other hand, firms like HP, Casio, and Sharp aimed their products at more conservative but familiar markets, i.e., consumers of calculators and electronic organizers. For example, HP's “The Road
Warrior's Weapon of Choice" advertising campaign for their 100LX device in 1993 was directed at salespeople who spent much of their time on the road.

Given the relatively slow market acceptance of handheld computing devices, the firms targeting broader markets were very disappointed with their product sales. In 1 year of business, AT\&T sold 10,000 EO devices, less than $10 \%$ of what it expected [41]. Amstrad and Tandy were also disappointed with early sales levels, e.g., Tandy lowered the price of the Zoomer by US\$200 in an attempt to stimulate sales [32]. All of these firms exited the market in short order. At the same time, however, firms with more conservative target markets and thus lower expectations stayed in the emerging handheld industry. For example, although HP sold less than 100,000 handheld units in its 1 st year, it considered this level of market acceptance to be "better than expected" [20].

Variation in expectations about market development also originates inside a firm, with conflicting perspectives potentially coming from development groups, management, and the corporate board within a single firm. At Polaroid, the top management team and the engineers engaged in digital imaging had widely divergent visions of how large and important the market for hard copy output would be in a digital world, based on conflicting mindsets at different levels of the organization [73]. Differences also exist between corporate and subsidiary decision makers. For example, consider the eventual fate of AT\&T's EO handheld computing device. AT\&T corporate had very different expectations than EO management and EO engineers. Although EO's CEO, Bob Evans, felt that the original market forecasts in his company were "not credible," the management at AT\&T corporate still believed that there was a large market for a handheld computing device with communication capabilities [32]. EO managers expected to iterate through a few product versions before they could "get it right," therefore initially targeted a broad customer base, and undertook a "market morphing" experimentation strategy [32]. As noted by CEO Bob Evans, "If you hit it right and succeed with the first product, it's wonderful, but you need the customer experience" [32]. 
Based on early market feedback to the EO, management decided that it should be targeting the upper $20 \%$ of cellular phone users. This customer group required a different combination of product functionality, so engineers were already working on the next generation product before EO was even introduced. In fact, a fully functioning prototype had been completed by the spring of 1994 and was scheduled for launch in December 1994. Yet, by August 1994, AT\&T corporate management decided to exit this industry only a year after it had entered. EO managers felt they had "learned what the customer really wanted" just as the company was exiting the market [32].

While product development was progressing at EO, AT\&T corporate was pursuing additional partners and investors to share the financial burden of developing this new marketefforts that were eventually unsuccessful [60]. In this case, corporate's aggressive expectations led them to be more disappointed in the industry's slow development than the EO management, and therefore, without additional investors, the board voted to abandon this industry. Carl Ledbetter, former president of AT\&T Consumer Products and EO board member, issued the following statement [24]: "We are disappointed that EO must close. But, given the slow development of the personal communicator market generally, and the low acceptance of EO's products, AT\&T believed it would not be prudent for AT\&T to invest more in EO without additional financing from other investors."

\subsubsection{Strategic Importance of the Emerging Industry}

The other major factor that explains whether a firm remains committed to a new industry as opposed to exiting is the strategic importance of the emerging industry to the firm. Is the emerging industry core to the firm's future strategy and identity or peripheral? A firm may be more willing to overlook disparities between expected and actual performance if an industry is believed to be central to the firm's future. And likewise, a firm will be less willing to commit to a peripheral industry. For example, Christensen and Bower [23] show that firms in the disc drive industry were less willing to sustain investments in emerging market segments that were viewed as small and peripheral relative to the firm's existing customer base. Similarly, we find that different levels of emerging industry strategic importance help explain firm exit, in this case, by moderating the relationship between unmet expectations and a firm's exit decision. Even if expectations are not met, if an emerging industry is strategically important, an organization is more likely to persist.

Strategic importance varies by the prior industry of new entrants. In digital cameras, $64 \%$ of firms from the computer industry that entered before the mini shakeout had exited by 2001. For firms that made computer peripherals, digital cameras were yet one more device to connect to a PC. A typical example is Best Data, a small vendor of computer peripherals, modems, and graphic cards that entered the market in 1996 and then quickly exited in 1997 when sales failed to materialize. Intel also entered the market in 1997 in the hope of influencing industry standards with a PC peripheral camera, but subsequently exited the industry. Forrester, a market research firm aptly captured the situation with the heading "Digital imaging is the 'flavor of the month' for the PC industry" in a report from 1997 [69].

In contrast, for analog camera makers, digital cameras were a direct substitute for their core business; without a presence in the emerging market, these firms faced declining sales. Only $40 \%$ of firms that made analog cameras exited, and many of these were small firms or primarily OEMs such as Chinon that were acquired. As one industry participant noted, "one can say it [digital photography] is a matter of life and death for some companies, notably Kodak and Fuji” [12].

Firms in the same industry can experience different levels of commitment to an emerging industry based on firm-level factors. In particular, organizational identity has been shown to play an important role in whether managers are supportive of new technologies and markets [71]. Analog photography firms that viewed imaging as a central core part of their identity remained committed to the emerging industry. For instance, Fuji defined itself as an "Information and Imaging" company, and this organizational identity facilitated its entry into digital imaging [72]. In contrast, Agfa, which viewed itself as a graphic arts and healthcare imaging company exited the US digital camera market in 2001 and the global market in 2002.

Firms introducing handheld computing devices also had different perceptions of the strategic importance of the new industry. AST, for instance, abandoned this industry quickly since it was not a comfortable fit with the company's line of laptop computers [28]. Similarly, companies like IBM and Compaq delayed product introductions due to lackluster industry sales, instead focusing on selling their other computer products. As stated by Bill Lempesis, president of Lempesis Research, "By not being on the market today are you missing anything? The answer is no. They are not flying off the shelves. People are reassessing, reevaluating" [68].

On the other hand, Sony had a different perspective of the opportunity related to this industry. According to Brian Sroub, then vice president of sales and marketing for Magic Link (a Sony partner in the handheld computing industry), "By the end of the century, as the infrastructure matures and standards are developed, there is going to be a huge revenue opportunity for people who are capable of sending messaging and entertainment through the service... We have lots of cards to play where hardware is in overall support of our software. This is an old strategy for Sony, where we get in on the hardware and then get increasingly involved on the software side." Sensing an early opportunity, Sony marketed their Magic Cap device 
between 1994 and 1996. Given the strategic importance of this industry to Sony, they did not abandon it. Instead, Sony re-entered again in 2000 with a device that used the Palm operating system (the same operating system used in the hugely successful Palm Pilot) and currently offer a variety of handheld computing devices.

Finally, within a firm, managers in different parts of the organization or at different hierarchical levels may view the emerging industry as more or less strategically important. At Fujifilm, when digital imaging was first broken out into a separate division with its own profit and loss, a group of middle managers challenged the commitment of senior management to digital imaging. They wrote a white paper that argued, at its core, Fuji was a specialty chemical company and rather than maintaining its identity as an imaging and information company, the organization should redefine itself and emphasize non-imaging specialty chemical markets over digital imaging [72].

\subsection{Apple Computer's Early Exit Decision in these Emerging Industries}

To better understand the interactions among the elements of our proposed framework, we compare and contrast the experience of Apple Computer in the digital imaging and handheld computing industries. Since Apple has been the subject of several case studies (e.g., [80]), we do not present an extensive historical background here. Suffice it to say that John Sculley was recruited in 1983 to raise Apple's financial results by building on their core capabilities in graphics and design by focusing on desktop publishing as well as the education market.

To implement this strategy, Apple carefully studied the emerging digital imaging and handheld computing industries. Apple created the Newton research group to develop the next generation of more personal and intimate computing devices. A product concept involving pen-based input (intelligent ink, handwriting recognition) and communication functions was approved in early 1990. Since MacIntosh computers were widely used in graphic arts and desktop publishing applications, Apple's digital camera was part of a broader effort to extend its influence in the imaging category. The camera was developed within the Imaging Products division, a group that announced a personal Laserwriter printer as well as Photoflash photo editing software, before it entered the digital camera arena. In that context, the digital camera was one small piece of an effort that itself was relatively new.

Although many different electronic organizers were introduced during the 1980s (e.g., [46]), significant attention about the potential opportunity for a new industry did not occur until Sculley raised expectations in 1992. During the January 1992 Winter Consumer Electronics Show, Sculley coined the term "personal digital assistant" to describe Apple's next great consumer product that would essentially be a personal communicator and information manager [15, 51]. Later that year in his address during the MacWorld Conference, Sculley peaked industry expectations that the convergence of several digital technologies would result in a new US $\$ 3.5$ trillion industry. Interestingly, Apple made no significant comments on the digital imaging industry.

Given the magnitude of Sculley's vision, many firms believed that the personal digital assistant concept was the "next big thing" (e.g., [10]). As a result, several significant players rushed to develop key strategic alliances in order to deliver the required technology, product, and infrastructure (e.g., [32, 51, $53,66,78])$. The prospect of setting technological standards for this emerging industry was at the forefront of many firms' decisions to bring their products to market as quickly as possible, even at the expense of introducing products that were not quite ready [32]. Apple shipped their Newton MessagePad in August 1993.

Whereas the Apple Newton received broad press coverage long before its initial announcement, Apple's first digital camera was discussed publicly at a US MacWorld convention only 1 month before its formal announcement at MacWorld Tokyo in February 1994. In addition, the camera was not considered important enough to mention in the annual report. Wall Street analysts at the time all commented on the announcement of the Apple Newton, but none mentioned the digital camera when it was initially announced. The one analyst that did mention the digital camera-in January 1995 - devoted two paragraphs to the Newton and in a section on Printers/Peripherals wrote, "Apple also sells a digital camera for use in graphics work on a PC" [65].

Our discussion to this point suggests that the Newton product was strategically important to Apple. According to Janet Cole, an analyst with Dataquest, "I don't believe they are betting the farm on Newton... but if they want to expand and grow, this is important" [26]. Moreover, Apple's plan was to make key parts of the Newton platform into an industry standard from which it could earn royalties. Unlike all the other competitors, Apple signed on six licensees and four distribution partners in vertical and foreign markets [51]. Despite earning a low margin on the hardware, Apple expected to make a healthy return on royalties from software as well as other licenses and accessories. At the same time, Apple's low key actions with respect to the digital imaging industry strongly suggest that it was relatively unimportant from a strategic perspective.

Over the course of its participation in the digital imaging industry, Apple shipped only three digital cameras: the Quicktake 100 in 1994, the Quicktake 150 in 1995, and the Quicktake 200 in 1997 before exiting the market in 1998. Although each of these cameras was designed by Apple, they all were heavily based on technology Kodak used in its own digital cameras, including Kodak CCD sensors for image 
capture. Apple's initial goals for the product were modest. The product line manager for the QuickTake 100 noted in 1994, "It won't be a mainstream computer product, save for computer enthusiasts and early adopters. It will be aimed at the business community initially...what we're finding is that mass merchants want something below $\$ 500$ " [63]. These modest goals appear to have been met initially; for example, Apple noted in a June 1996 press release that it was the world market leader in unit digital camera sales [57].

In contrast, Apple clearly had high early expectations for the Newton handheld device. In Sculley's mind, "we believe that Newton will be seen as the defining technology of the digital age" [26]. Not surprisingly, Apple envisioned a mass market. As stated by Ken Wirt, then director of marketing for Newton, "We think this is a market that is at least as big as the personal computer market. There are an estimated 100 million installed PCs in the world today" [26]. Apple's high expectations for the handheld computing industry went unfulfilled. While they sold 50,000 Newtons in the 1st month, sales levels plummeted in the ensuing months so that cumulative sales of the Newton 1 year after introduction were only 90,000 units, well short of even conservative expectations of 150,000 units [15]. Microsoft Chairman Bill Gates is quoted as saying that the Newton may have "set the category back a couple of years" [38].

Given its strategic importance, however, Apple did not abandon the emerging handheld computing industry between 1993 and 1998. Instead, Apple lowered its expectations by shifting to vertical market applications (e.g., [16]). As observed by Joseph Graziano, then Apple's CFO and acting GM of the Personal Interactive Electronics Division, "We always knew that there'd be business users for the Newton. But our marketing message and approach at launch were wrong" [34]. To exploit these markets, Apple worked closely with specialized value added resellers that could develop customized hardware and software as well as with software developers (by 1995, 300 out of Newton's 380 applications were for vertical markets; [16]). In addition, Apple developed and introduced several new devices including the MessagePad 110, MessagePad 120, MessagePad 130, MessagePad 2000, MessagePad 2001, and the eMate 300 (targeted at education markets). It was reported that by September 1995, Apple had invested about US\$300 million in the Newton so far [15].

Although there are several theories as to why Apple killed the Newton (e.g., [48]), the one that has the most empirical support involves a change in the strategic importance of this industry to Apple. During the 1998 timeframe, Apple was struggling financially and probably at its lowest point [80]. Apple did not have the financial resources to stray too far from its core business which at the time centered on the Mac OS operating system [48]. The company needed to cut costs in order to become profitable again, and the Newton effort had been a financial drain.
By 1998, the competitive environment in these two industries had shifted. For example, there were 52 new entrants in the digital camera industry between 1995 and 1997 and as of 1998, sales growth was still slow; in the handheld computing industry, Microsoft had entered with its Windows CE software and had begun to establish relationships with significant hardware firms like Compaq, IBM, and Dell (e.g., see HPD [27] for a history of Windows CE). Due to increased competition, a slower sales takeoff than anticipated, and low strategic importance, Apple exited the digital imaging industry in 1998. Since the strategic importance of the handheld industry for Apple had also diminished, Apple decided to exit this industry in the same year.

This example demonstrates that Apple's decision to exit the emerging digital imaging and handheld computing industries was a function of unmet expectations as well as the perceived strategic importance of the new industries to the company. As the strategic importance of the handheld computing industry to Apple diminished, Apple's exit decision became easier. Together, this decision history is consistent with the idea that strategic importance of the emerging industry moderates the relationship between unmet expectations and a firm's exit decision.

Moreover, this example highlights that an understanding of Apple's exit decisions requires consideration of industry, intra-firm, and inter-firm level factors. For the digital imaging industry, Apple set their relatively low expectations based on the more conservative industry forecasts. For the handheld computing industry, however, Apple championed the concept of a personal digital assistant and thus was the one who created huge industry expectations. Our discussion of these two emerging industries also shows that there was a wide variation in expectations across the entrants. Apple clearly entered the digital imaging industry with different expectations than Kodak and Fuji, and had very different expectations of the handheld computing industry than firms coming from consumer electronics (HP, Casio, and Sharp) or telecommunications (AT\&T, Motorola, Bell South). Within a firm, consideration of the differing opinions of the CEO, management, and product developers is also important to completely understand Apple's decision to abandon the handheld industry. For Apple, the perspectives of these various stakeholders were important in shaping the firm's beliefs of the new industry's strategic importance.

\section{Discussion and Conclusions}

In this paper, we challenge the widely accepted model of industry evolution in which the emergence of new industry is characterized by a smooth progression of three stages: (1) high levels of entry with an increasing overall number of firms, (2) a shakeout in which the total number of firms 
decreases significantly, and finally, (3) stability, when the market matures with little change in the total number of firms. While this model holds for many new industries, we provide evidence that a large proportion of industries experience an additional stage of disillusionment, where many firms abandon their innovative efforts in a new industry before it has completely developed. We term this additional stage a mini shakeout. In a sample of 24 new product industries, we find that $46 \%$ experienced a mini shakeout. Perhaps not surprisingly, we find that mini shakeouts are much more likely to occur in an industry when sales take a long time to materialize. On average, the time from initial commercialization of an innovation to sales takeoff is 21 years for industries that experience a mini shakeout vs. only 8.5 years for industries that do not. Some firms simply get tired of waiting and choose to exit the industry.

Using inductive case studies of handheld computers and digital cameras, we then develop a conceptual model to distinguish those firms that exit from those that remain committed. The drivers of the exit in the major shakeout of traditional models are primarily related to firm performance. For instance, poorly managed less innovative or smaller firms that do not have a competitive cost position exit. The tacit assumption is that the winners survive and the losers exit. In the mini shakeout, however, the industry has yet to develop and there are no obvious winners or losers. Instead, we argue that factors explaining exit may relate to patience and management of expectations. In particular, we find two factors that differentiate firms that chose to exit from those that do not: (1) expectations about the industry's development, including how quickly the market would grow and what segments would develop first, and (2) the level of strategic importance the industry held for the firm. Both of these factors varied significantly for firms that entered the two industries we examined. The variation in expectations originated from multiple levels, including prior industry affiliation, idiosyncratic firm history, and intra-firm dynamics.

In our conceptual framework (see Table 2), we propose that once actual market data start to be available, the variation in expectations leads some firms to have clearly unmet expectations while others do not. For those firms that are disappointed in their performance, whether they abandon the industry or not hinges on the strategic importance of the industry to the firm. For instance, even though photography firms had unmet expectations in digital cameras, most were unwilling to exit a market that they considered critical to their future.

Conceptualizing exit as a choice variable is a unique contribution of this paper. While the factors driving entry into an industry have been studied extensively (e.g., [33, 54]), much less attention has been placed on decisions to exit that are not based simply on competitive necessity. The burgeoning literature on real options has started to address the strategic importance of the choice to exit $[3$,
52], but this work does not examine how those choices happen within a firm. It simply proposes that those choices are important and can create value. Similarly, limited research in entrepreneurship has examined why start-ups with similar levels of performance have a differential propensity to exit and found that non-monetary factors affect firm profit thresholds [29, 64], but this work does not examine the exit decisions of established firms.

While we contribute to understanding the drivers of exit choices early in an industry's emergence, we believe that much work remains. Testing our conceptual framework with a larger sample of firms and industries would be a first step. In addition, it would be interesting to examine the role of feedback effects that unmet expectations and firm exit have on the evolution of the industry - it may be that industries that have a virtuous cycle between exceeding expectations and firm entry decisions develop faster than industries that experience a vicious cycle between unmet expectations and firm exit decisions. While our study documents the inverse relationship between time to sales takeoff and firm decisions to continue their innovative activity, the nature of the causality may be questioned. This highlights the need for future research that systematically surveys firms at the time that the expectations are being formed and gathers evidence from industry analysts, forecasts, etc. on multiple emerging industries, to investigate the variation in the time to sales takeoff experienced by the industry.

Additional research is also needed in understanding proactive exit. While recent research has begun to draw attention to inter-temporal economies of scope and firm decisions to redeploy resources by exiting some industries while entering others [37], linkages between diversification patterns over the firm life cycle and life cycles of the industries that they choose to enter into and exit from will help further the literature on both firm and industry evolution. Further study of possible learning across industries could lead to important insights into firm strategies. Do firms apply learning from late exits (during the shakeout period) in one industry to its early exit decisions (during the mini shakeout period) in other emerging industries? Do firms learn from the opportunity costs of early exits in one industry and apply it to later exit decisions in other industries? We hope that our study calls attention to the need to examine deviations in the stylized trends observed in the industry evolution literature and concomitantly for a focus on exit decisions, in addition to entry, as firms invest in strategic renewal activities.

Acknowledgments Financial support from the Ewing Marion Kauffman Foundation is gratefully acknowledged. The paper has benefited from comments made by Steven Klepper as well as seminar participants at the Harvard Business School, MIT Sloan School, University of Maryland, and Stanford. We also thank the review team for their encouraging comments. All remaining errors are ours. 


\section{References}

1. Abernathy WJ, Clark KB, Kantrow AM (1983) Industrial Renaissance: producing a competitive future for America. Basic Books, New York

2. Abernathy WJ, Utterback JM (1978) Patterns of industrial innovation. Technol Rev 80(7):40-47

3. Adner R, Levinthal DA (2004) What is not a real option: identifying boundaries for the application of real options to business strategy. Acad Manag Rev 29(1):74-85

4. Agarwal R (1998) Evolutionary trends of industry variables. Int J Ind Organ 16(4):511-525

5. Agarwal R, Bayus BL (2002) The market evolution and sales takeoff of product innovations. Manag Sci 48(8):1024-1041

6. Agarwal R, Bayus BL (2004) Creating and surviving in new industries. In: Baum JAC, McGahan AM (eds) Business strategy over the industry life cycle: advances in strategic management. JAI/Elsevier, Oxford, pp 107-130

7. Agarwal, R. and S. Braguinsky (2014), "Industry evolution and entrepreneurship: Steven Klepper's contributions to industrial organization, strategy, technological change and entrepreneurship," Strategic Entrepreneurship Journal (forthcoming)

8. Agarwal R, Gort M (1996) The evolution of markets and entry, exit and survival of firms. Rev Econ Stat 78(3):489-498

9. Agarwal R, Tripsas M (2008) Technology and industry evolution. In: Shane S (ed) Handbook of technology and innovation management. Blackwell Publishing, MA, pp 3-56

10. Allen J (2008) Visions of the next big thing: computerization movements and the mobilization of support for new technologies. In: Kraemer K, Elliott M (eds) Computerization movements and technology diffusion: from mainframes to ubiquitous computing. Information Today Press, Medford, pp 145-172

11. Aranoff S (1997) The digital cameras-lessons from (recent) history. Future Image Rep 5(1):16

12. Australian Stock Exchange Company Announcements (2000), Ixla Ltd chairman's address to shareholders. 11/8/0,1

13. Baum JAC, McGahan AM (2004) Business strategy over the industry lifecycle: advances in strategic management 21 . JAI/Elsevier, Oxford

14. Bayus BL, Jain S, Rao A (1997) Too little, too early: introduction timing and new product performance in the personal digital assistantindustry. J Mark Res 34(2):50-63

15. Bayus BL, Kang W, Agarwal R (2007) Creating growth in new markets: a simultaneous model of firm entry and price. J Prod Innov Manag 24(2):139-155

16. Bennahum, D. (1995), "The return of the PDA," marketing computers, http://memex.org/thereturnofthepda.html (accessed January 12,2012 )

17. Benner MJ, Tripsas M (2012) The influence of prior industry affiliation on framing in nascent industries: the evolution of digital cameras. Strateg Manag J 33(3):277-302

18. Benner MJ, Tushman M (2002) Process management and technological innovation: a longitudinal study of the photography and paint industries. Adm Sci Q 47(4):676-706

19. Brown S, Eisenhardt K (1997) The art of continuous change: linking complexity theory and time-paced evolution in relentlessly shifting organizations. Adm Sci Q 42(1):1-34

20. Buckley, T. (1991), "a more aggressive HP," marketing computers, (November), 30

21. Carroll GR, Hannan MT (1989) Density delay in the evolution of organizational populations - a model and 5 empirical tests. Adm Sci Q 34(3):411-430

22. Christensen CM (1997) The innovator's dilemma: when new technologies cause great firms to fail. Harvard University Press, Boston
23. Christensen CM, Bower JL (1996) Customer Power, Strategic Investment, and the Failure of Leading Firms. Strateg Manag J 17(3):197-218

24. Edge Publishing (1994), "Wireless world: AT\&T/EO, Inc. to cease operations," Edge, 9(314), August 1

25. Eisenhardt KM (1989) Building Theories from Case Study Research. Acad Manag Rev 14(4):532-550

26. Enders, J. (1993), "Apple places big bet on Newton Personal Communicator," The Associated Press, (July 29)

27. HPC Factor (2005), "A brief history of Windows CE," http://www. hpcfactor.com/support/windowsce/ (accessed August 15, 2005)

28. Gardner W (1995) The choice of a new generation - once haplessly billed as the Rodney Dangerfield of computing, PDAs finally are getting some respect. Commun Week 552(April 10):34

29. Gimeno J, Folta TB, Cooper AC, Woo CY (1997) Survival of the fittest? Entrepreneurial human capital and the persistence of underperforming firms. Adm Sci Q 42(4):750-783

30. Golder PN, Tellis GJ (1993) Pioneer advantage - marketing logic or marketing legend. J Mark Res 30(2):158-170

31. Golder PN, Tellis GJ (1997) Will it ever fly? Modeling the takeoff of really new consumer durables. Mark Sci 16(3):256-270

32. Gomes-Casseres B, Leonard-Barton D (1997) Alliance clusters in multimedia: safety net or entanglement? In: Yoffie D (ed) Competing in the age of digital convergence. Harvard Business School Press, Cambridge, pp 325-369

33. Gort M, Klepper S (1982) Time paths in the diffusion of product innovations. Econ J 92(367):630-653

34. Hall, M. and I. Swartz (1994), "Graziano: Newton off the rocks," MacWeek, (August 15), 1

35. Hannan M, Freeman J (1989) Organizational ecology. Harvard University Press, Cambridge

36. Helfat CE, Eisenhardt KM (2004) Inter-temporal economies of scope, organizational modularity, and the dynamics of diversification. Strateg Manag J 25(13):1217-1232

37. Highfield, R. (1993), "Boxing clever," Esquire, (May)

38. Hill, G. and J. Carlton (1994), "Getting personal," Wall Street Journal, (February 11), R6

39. Jerney J (1995) Talking with Palm Chair Jeff Hawkins. Pen Comput 2(January):32-34

40. Jovanovic B, MacDonald GM (1994) The life cycle of a competitive industry. J Polit Econ 102(2):322

41. Keller, J. (1994), “AT\&T's EO to focus on cellular phones as market for data devices proves slow," Wall Street Journal, (February 1), B6

42. King AA, Tucci CL (2002) Incumbent entry into new market niches: the role of experience and managerial choice in the creation of dynamic capabilities. Manag Sci 48(2):171-186

43. Klepper S (1996) Innovation and industry shakeouts. Bus Econ Hist 25(1):81-89

44. Klepper S (1997) Industry life cycles. Ind Corp Chang 6(1):145-181

45. Klepper S, Graddy E (1990) The evolution of new industries and the determinants of market-structure. Rand J Econ 21(1):27-44

46. Koblentz, E. (2005), "The evolution of the PDA: 1975-1995," http:// www.snarc.net/pda/pda-treatise.htm (accessed August 20, 2005)

47. Lewis, P. (1992), "The executive computer; a computer or not? Apple readies its Newton," New York Times, (July 12), 9

48. MacNeill, D. (1998), "Why did Apple kill the Newton?" Pen Computing, 5 (June)

49. MacWeek (1989), "Eikonix bows out of retail digitizer market," (February 28), 81

50. Mahajan V, Muller E, Bass FM (1990) New product diffusion models in marketing - a review and directions for research. J Mark 54(1):1-26

51. McGahan A, Vadasz L, Yoffie D (1997) Creating value and setting standards: the lessons of consumer electronics for personal digital assistants. In: Yoffie D (ed) Competing in the Age of digital convergence. Harvard Business School Press, Cambridge, pp 227-264 
52. McGrath RG (1997) A real options logic for initiating technology positioning investments. Acad Manag Rev 22(4):974-996

53. Minishall T (1999) A resource-based view of alliances: the case of the handheld computer industry. Int J Innov Manag 2(3):159-183

54. Mitchell W (1991) Dual clocks - entry order influences on incumbent and newcomer market share and survival when specialized assets retain their value. Strateg Manag J 12(2):85-100

55. Olleros FJ (1986) Emerging industries and the burnout of pioneers. J Prod Innov Manag 3(1):5-18

56. Peltoniemi M (2011) Reviewing industry life-cycle theory: avenues for future research. Int J Manag Rev 13(4):349-375

57. Pihichyn, P. (1996), "Apple puts best face on gloom," Winnipeg Free Press, (June 4)

58. Porac JF (1997) Local rationality, global blunders, and the boundaries of technological choice: lessons from IBM and DOS. In: Garud R, Nayyar PR, Shapira ZB (eds) Technological innovation: oversights and foresights. Cambridge University Press, New York, pp 129-146

59. Rogers EM (1995) Diffusion of innovations. Free Press, New York

60. Rohrbough, L. (1994), "EO to close doors," Newsbytes News Network, (July 28)

61. Rosenkopf L, Tushman M (1994) The coevolution of technology and organization. In: Baum JAC, Singh J (eds) Evolutionary dynamics of organizations. Oxford University Press, New York, pp 403-424

62. Rothaermel FT (2001) Incumbent's advantage through exploiting complementary assets via interfirm cooperation. Strateg Manag J 22(6/7):687-699

63. Ryan, K. (1994), “Apple unveils personal laser printer," HFN, (January 10)

64. Scott-Morton FM, Podolny JM (2002) Love or money? The effects of owner motivation in the California wine industry. J Ind Econ 50(4):431-456

65. Smith Barney (1995), "Apple computer," (January 17), 5

66. Stieglitz, N. (2002), "Industry dynamics and types of market convergence: the evolution of the handheld computers market in the 1990s and beyond," http://www.druid.dk/uploads/tx_picturedb/ds2002651.pdf (accessed December 16, 2013)

67. Suarez FF, Utterback JM (1995) Dominant designs and the survival of firms. Strateg Manag J 16(6):415-430

68. The Financial Post (1994), "Personal digital assistant market rife with woes," (May 13), 38

69. The Forrester Report (1997), "Digital photos click," (November)

70. Tripsas M (1997) Unraveling the process of creative destruction: complementary assets and incumbent survival in the typesetter industry. Strateg Manag J 18(S1):119-142

71. Tripsas M (2009) Technology, identity, and inertia: through the lens of 'the digital photography company'. Organ Sci 20(2): $441-460$

72. Tripsas, M. (2013), "Exploring the interaction between organizational identity and organizational design in technological transitions," working paper

73. Tripsas M, Gavetti G (2000) "Capabilities, Cognition, and Inertia: Evidence from Digital Imaging,” Strateg Manag J 21(10/11):11471161

74. Tushman ML, Anderson PC (1986) Technological discontinuities and organizational environments. Adm Sci Q 31(3):439-465

75. Utterback JM, Abernathy WJ (1975) A dynamic model of process and product innovation. Omega 3(6):639-656

76. Utterback JM, Suarez FF (1993) Innovation, competition, and industry structure. Res Policy 22(1):1-21

77. Van de Ven AH, Garud R (1993) Innovation and industry development: the case of cochlear implants. Res Technol Innov Manag Policy 5:1-46

78. Van Wegberg, M. (1998), "Evolution and competition in the market for handheld computers," http://arno.unimaas.nl/show.cgi?fid=670 (accessed December 11, 2013)

79. Yin RK (1984) Case study research. Sage, Beverly Hills

80. Yoffie, D. and Y. Wang (2008), "Apple computer 2002," Harvard Business School Case Study 9-708-480 